\title{
Pectoralis major rupture: Presentation of two cases and review of 74 cases
}

\author{
Hubert YM Chao MD, Ralph T Manktelow MD FRCSC \\ Faculty of Medicine, The University of Toronto, Toronto, Ontario
}

\begin{abstract}
HYM Chao, RT Manktelow. Pectoralis major rupture: Presentation of two cases and review of 74 cases. Can J Plast Surg 1997;5(2):118-122. Pectoralis major rupture is uncommon. Injury usually occurs from sporting activities. The incidence and management of pectoralis major rupture is not well known, despite 74 case reports in the English language literature over the past 34 years. Two cases of chronic pectoralis ruptures and their successful surgical management are described. A review of the literature shows that most injuries occur at the humeral insertion, and most are complete ruptures. Distinguishing between complete and partial ruptures is important. Complete ruptures are best treated surgically in the acute situation. When chronic complete ruptures present, surgical repair yields fair to good results. Acute partial ruptures can be effectively managed conservatively or with surgery. Chronic partial ruptures can be managed surgically with good results, following unsatisfactory conservative management in the acute situation.
\end{abstract}

Key Words: Incidence, Management, Pectoralis major, Rupture

\section{Rupture du grand pectoral : présentation de deux cas et revue de $\mathbf{7 4}$ autres}

La rupture du grand pectoral est un phénomène rare. La lésion découle habituellement d'activités sportives. L'incidence et le traitement de la rupture du grand pectoral sont mal connus malgré le fait que 74 cas aient été recensés dans la littérature de langue anglaise au cours des 34 dernières années. Deux cas de rupture chronique du grand pectoral traités chirurgicalement avec succès sont décrits ici. Un survol de la littérature révèle que la majorité de ces blessures surviennent au niveau de l'insertion humérale et dans la plupart des cas, la rupture est totale. Il est important de distinguer les ruptures totales des ruptures partielles. Il est préférable de traiter chirurgicalement les ruptures totales aiguës. En présence de ruptures totales chroniques, la correction chirurgicale donne habituellement des résultats de passables à bons. Les ruptures partielles aiguës sont quant à elles traitées efficacement avec ou sans chirurgie. Les ruptures partielles chroniques peuvent être traitées chirurgicalement avec de bons résultats après l'échec des mesures thérapeutiques conservatrices appliquées au contexte aigu.

$\mathrm{P}$ ectoralis major rupture is uncommon. The relative incidence of partial and complete ruptures of the pectoralis major, in acute and in chronic presentations, is not well known, and management of these injuries is not well documented. Weight lifting is the most common cause of pectoralis major rupture, and the bench press exercise accounts for a large portion of occurrences (1-4). Other causes include windsurfing $(1,5)$, football $(6,7)$, wrestling $(5,8-10)$, hockey $(11,12)$ and falls $(13-15)$. This paper identifies 74 cases reported in the English language literature in the past 34 years and describes two additional cases and their successful management. The relative incidence of partial and complete ruptures in acute and chronic presentations is discussed. Through review of the literature, the most appropriate management was determined. Anatomy, classification of injury and diagnosis are reviewed.

Correspondence: Dr RT Manktelow, Head, Division of Plastic Surgery, The Toronto Hospital - Western Division, West Wing 5-835, 399 Bathurst Street, Toronto, Ontario M5T 2S8. Telephone 416-603-5588, fax 416-603-5597

\section{Case 1}

\section{CASE PRESENTATIONS}

A 24-year-old physical education instructor injured his left pectoralis major. At the time of injury, he had been lifting weights for a number of years. While completing his regular weight lifting program, he was bench pressing a $42 \mathrm{~kg}$ barbell (his maximum). As he was abducting his arms in a transverse plane stretching, he felt a burning sensation at the humeral insertion of the left pectoralis major. He did not continue his program. He had persistent symptoms of pain, decreased range of motion, weakness and deformity. One week after injury, ecchymosis became evident in his arm extending to his elbow. Pain was aggravated by shoulder extension and by motion from jogging. This pain limited his active range of motion. He noted weakness and chest cramps when exercising. Also the pectoralis major would bunch into a ball on the chest wall when contracting. The injury prevented the patient from exercising and performing his regular activities as a physical education instructor. The patient did not use anabolic steroids.

He sought treatment from several surgeons. The common 


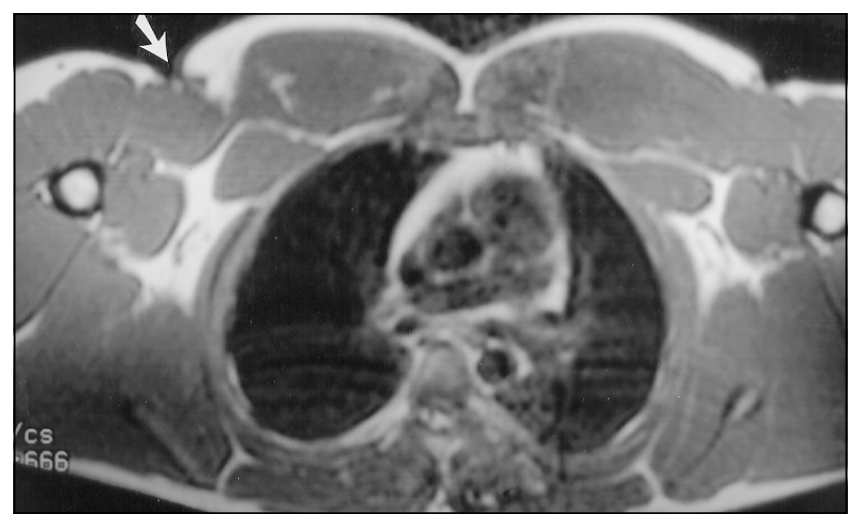

Figure 1) Tranverse magnetic resonance image section from case 2 demonstrates a right pectoralis major rupture. Note that the partial rupture has a defect anteriorly and with retraction towards the origin

opinion was that successful surgical repair was highly questionable, and some surgeons refused repair as an option. Because the level of functional impairment was unacceptable, the patient presented to the senior author for another opinion. Operative exploration and possible repair were offered, and surgery was performed 22 months following injury. The chest was exposed through a deltopectoral incision extended diagonally across the chest. A complete rupture of the pectoralis major from the humeral insetion was found. The tendon had withdrawn into the muscle, and had inverted muscle fibres in that location. The pectoralis major was dissected from the deltoid. Three strips of fibrous scar tissue had developed and were attached to the distal muscle. Because there was no tissue present at the lateral lip of the bicipital groove to allow adequate suturing, two holes were made. The three strips were drawn through, pulled back on themselves and interwoven into the muscle. A portion of the clavicular head was pulled down to the lower pole of the insertion and sutured to the deltoid insertion. The wound was closed, and the arm was splinted across the chest. Rehabilitation was started eight weeks after surgery.

The patient reported alleviation of pain and correction of deformity immediately following surgery. Eight months following surgery, he started weight lifting. He regained full range of motion by 12 months following surgery, and the patient had returned to normal activities at work with no impairment.

\section{Case 2}

This patient is a powerlifter who at 22 years of age injured his right pectoralis major. He was bench pressing fast repetitions of $180 \mathrm{~kg}$ (maximum $242 \mathrm{~kg}$ ) when he heard a tear at the humeral insertion of the pectoralis major. Pain began within a hour, but subsided over a few days. Weakness persisted, and he could bench press a maximum of only $82 \mathrm{~kg}$. Deformity was evident by a depression at the lateral chest. Range of motion was normal. The patient had a history of anabolic steroid use. He had been using steroids for five weeks, following a 1.5 year hiatus from steroids. He presented one month postinjury with persistent weakness and deformity. The posterior lamina of the pectoralis major was palpable at the axilla, and a partial rupture of the pectoralis major was suspected. Mag-
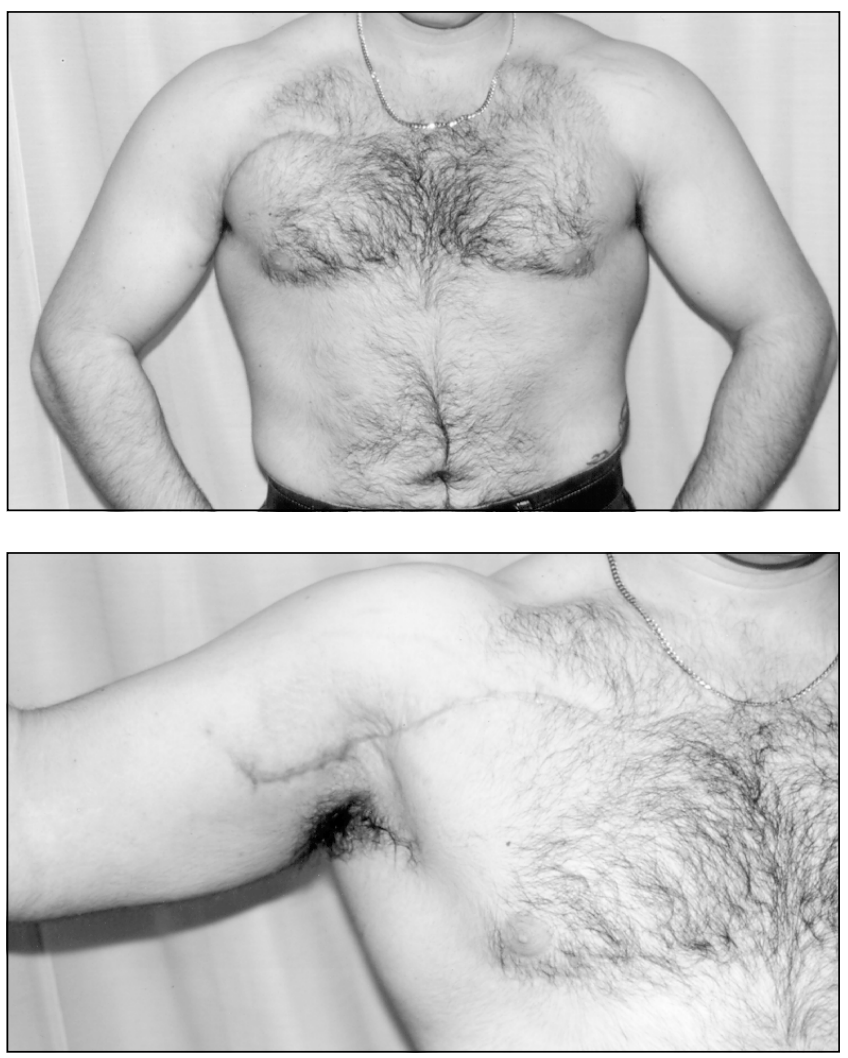

Figure 2) Top Postoperative anterior view of case 2 demonstrates satisfactory bilateral symmetry and fullness of the lateral chest. Bottom Postoperative view with the arm abducted shows surgical scar and continuity of the anterior axillary fold

netic resonance imaging was performed and confirmed the same (Figure 1). Conservative treatment was recommended. However, at six weeks postinjury, he sustained a further injury during a crosshand punch while exercising with a punching bag. This episode resulted in increased weakness. At this point surgical exploration was considered necessary.

Fourteen weeks following the initial injury, surgery was performed. An incision was made along the deltopectoral groove, extending transversely across the chest and extending inferiorly along the arm. The central portion of the pectoralis major was found avulsed from the humeral insertion. The clavicular portion and a $2 \mathrm{~cm}$ wide strip of the inferior sternocostal portion were intact. Approximately $80 \%$ of the muscle had been avulsed. The avulsed portion was sutured to the intact sternocostal portion at its insertion. The wound was then closed and the arm was splinted across the chest. The patient began gentle stretching five weeks following surgery. Deformity was not evident. At nine weeks following surgery, he had full range of motion and was lifting progressively heavier weights with no discomfort. At 15 weeks following surgery he was bench pressing $118 \mathrm{~kg}$, and at 27 weeks after surgery he was bench pressing $178 \mathrm{~kg}$ (Figure 2).

\section{ANATOMY}

The pectoralis major is a fan-shaped muscle that extends from the chest, forming the front wall of the axilla and inserts on the humerus. There is a clavicular portion and a sternocos- 
tal portion. The clavicular portion originates from the medial one-half to two-thirds of the clavicle to insert on the lateral lip of the bicipital groove of the humerus. The sternocostal portion originates from the sternum, second to sixth costal cartilages and the aponeurosis of the external oblique. It passes upward and laterally from the origin to insert on the humerus behind and more proximal to the clavicular portion. The tendon of insertion is $1 \mathrm{~cm}$ long anteriorly, $2 \mathrm{~cm}$ long posteriorly and $5 \mathrm{~cm}$ wide (1). The pectoralis major along with other muscles functions in adducting, flexing and internally rotating the humerus. The pectoralis major is the dominant muscle in adducting the humerus in the transverse plane (16). Adduction in the coronal plane involves primarily the latissimus dorsi, teres major and rhomboids, with the pectoralis major playing a secondary role.

\section{CLASSIFICATION OF INJURIES}

Tietjen (17) detailed a useful classification for injuries to the pectoralis major. Class I is a contusion or sprain. Class II is a partial rupture, usually at the inferior sternocostal portion. Class III injuries are complete ruptures, and there are four subclasses. Class IIIA ruptures occur at the muscle origin. Class IIIB ruptures occur at the muscle belly. Class IIIC ruptures occur at the musculotendinous junction. Class IIID ruptures occur at the muscle tendon insertion.

\section{INCIDENCE}

Of the 76 cases (Table 1) reported, 41 injuries occurred at the humeral insertion, 11 injuries occurred at the musculotendinous junction and three injuries at the muscle belly. The remainder of the cases demonstrated an anatomical defect but the site of injury was unknown. Wolfe et al (5) had reported series of 19 patients who were all diagnosed with injury at the humeral insertion. This review shows that most injuries occur at the humeral insertion, but injuries can also occur at other sites.

Of the 76 cases, complete ruptures were reported in 35 cases (30 cases at the humeral insertion and five cases at the musculotendinous junction), and partial ruptures in 22 cases (10 cases at the humeral insertion, six cases at the musculotendinous junction and six cases at an undetermined site). The remainder of the cases demonstrated an anatomical defect, but the degree of injury was unknown. Kretzler et al (3) found 15 complete ruptures and only one partial rupture among the 16 cases treated surgically. This review shows that complete ruptures are more common than partial ruptures.

The review also confirms that weight lifting is the most common cause for pectoralis major injury. Of the 76 cases reviewed, 34 cases were due to weight lifting, with 16 of these known to be due to the bench press exercise. Six cases were due to falls; four cases were due to wrestling; three cases were due to football; two cases were due to hockey, two cases were due to windsurfing, and 25 cases were attributed to other causes or were unspecified.

Rijnberg and Van Linge (2) have suggested that simultaneous use of steroids and growth hormone may result in the pectoralis major tendon poorly adapting to the increased de- mand of hypertrophic muscle. Thus, the tendon would risk rupture. Wolfe et al (5) reported that four of 12 patients admitted to using anabolic steroids. One of the two cases presented here had used anabolic steroids.

\section{DIAGNOSIS}

Considerable description of symptoms and signs of pectoralis major rupture have been reported in the literature $(1,3,7,8$, 12-14,18,19). At the time of injury, a sharp pain or tearing sensation is experienced. Ecchymosis may form in the chest, axilla or arm. Swelling may be evident. Range of motion is diminished, and there is pain and weakness with adduction and internal rotation and flexion of the shoulder. In complete ruptures, loss of the axillary fold may be observed, and the axilla may appear webbed when the arm is abducted. However, fascial tissue may mask complete ruptures on inspection and palpation. In these cases, magnetic resonance imaging is useful in defining the extent of injury (6). Differentiation between complete musculotendinous junction ruptures (class IIIC) and ruptures at the humeral insertion (Class IIID) may be difficult. Class IIIC ruptures have ecchymosis of the axilla $(2,7,18)$, while class IIID includes ecchymosis of the $\operatorname{arm}(3,7,12)$. However, Park et al (14) reported a case of class IIIC rupture with echymosis of the arm.

$\mathrm{X}$-rays may confirm the diagnosis of pectoralis major rupture by demonstrating soft tissue swelling and absent pectoralis major shadow $(1,2,7,8,12-14,18)$.

Patients who present with chronic partial or chronic complete ruptures (having been injured for greater than six weeks) report weakness $(1,3,5,13,15,19,20)$. Pain was a feature of the five chronic complete ruptures reviewed $(1,3$, 11,13 ) and was present in case 1 . However, only one of the six patients with chronic partial ruptures was described as having pain (19). Pain may be caused by contracting muscle retracting medially against adhesions. In the case of partial ruptures, pain may be less of a factor because intact muscle fibres prevent the muscle from retracting medially.

\section{TREATMENT}

The literature supports surgical repair of acute complete ruptures. Of the 16 cases of surgically repaired acute complete ruptures $(2,5-7,11-14,18)$, the only problematic result was with Zeman et al, Case 2 (7). This case was described at eight weeks postrepair as having "excellent motion and strength but complained of mild pain in the area of the repair." The other 15 cases were described as successes with criteria such as returning to full function, regaining full range of motion, regaining full strength, or the absence of pain. The literature does not recommend conservative management of complete ruptures. The six reported cases of chronic complete ruptures presented with pain and weakness. Each of the cases was subsequently treated by surgery, and each was effectively relieved of pain and weakness. However, surgical repair of chronic complete ruptures is more difficult than surgical repair of acute cases because of adhesions, muscle retraction and atrophy (6). Two of the six cases of chronic complete rupture reported by Kretzler et al (3), cases 14 and 15, were 
TABLE 1: Pectoralis major rupture cases reported from 1961 to 1995

\begin{tabular}{|c|c|c|c|c|c|c|c|}
\hline Author (reference) & $\begin{array}{c}\text { Case } \\
\text { number }\end{array}$ & Mechanism & Site & Extent & Class & Presentation & Treatment \\
\hline \multirow[t]{2}{*}{ Marmor et al (10) } & 1 & Bench press & Insertion & Partial & II & Acute & Surgery \\
\hline & 2 & Wrestling & MT junction & Partial & II & & Conservative \\
\hline Schechter and Gristina (15) & 1 & Fall & MT junction & Partial & II & Chronic & Surgery \\
\hline Park et al (14) & 1 & Fall & MT junction & Complete & IIIC & Acute & Surgery \\
\hline \multirow[t]{7}{*}{ McEntire et al (13) } & 1 & Fall & Belly & & & Acute & Surgery \\
\hline & 2 & Fall & Belly & & & Acute & Surgery \\
\hline & 3 & Fall & Insertion & Complete & IIID & Acute & Surgery \\
\hline & 4 & Fall & Insertion & Complete & IIID & Acute & Surgery \\
\hline & 5 & Bench press & MT junction & Complete & IIIC & Chronic & Surgery \\
\hline & 6 & Other & Insertion & Complete & IIID & Acute & Surgery \\
\hline & 7 & Bench press & Insertion & Complete & IIID & Acute & Surgery \\
\hline Gudmundsson (9) & 1 & Wrestling & Unknown & Unknown & & & Conservative \\
\hline \multirow[t]{2}{*}{ Kawashima et al (18) } & 1 & Occupational & Belly & & & Acute & Surgery \\
\hline & 2 & Crush & MT junction & Complete & IIIC & Acute & Surgery \\
\hline Lindenbaum (20) & 1 & Bench press & Insertion & Partial & II & Chronic & Surgery \\
\hline \multirow[t]{7}{*}{ Zeman et al (7) } & 1 & Football & Insertion & Complete & IIID & Acute & Surgery \\
\hline & 2 & Football & MT junction & Complete & IIIC & Acute & Surgery \\
\hline & 3 & Weight lifting & Unknown & Unknown & & & Conservative \\
\hline & 4 & Other & Insertion & Complete & IIID & Acute & Surgery \\
\hline & 5 & Bull riding & Unknown & Unknown & & & Conservative \\
\hline & 6 & Auto accident & Unknown & Unknown & & & Conservative \\
\hline & 7 & Weight lifting & Insertion & Partial & II & Acute & Surgery \\
\hline Berson (8) & 1 & Wrestling & Insertion & Partial & II & Acute & Surgery \\
\hline Delport and Piper (12) & 1 & Hockey & Insertion & Complete & IIID & Acute & Surgery \\
\hline \multirow[t]{5}{*}{ Orava et al (11) } & 1 & Weight lifting & Insertion & Complete & IIID & Acute & Surgery \\
\hline & 2 & Weight lifting & Insertion & Complete & IIID & Acute & Surgery \\
\hline & 3 & Parachuting & Insertion & Complete & IIID & Chronic & Surgery \\
\hline & 4 & Hockey & Insertion & Partial & II & Chronic & Surgery \\
\hline & 5 & Other & Insertion & Complete & IIID & Acute & Surgery \\
\hline Jones and Matthews (4) & 1 & Weight lifting & Unknown & Unknown & & Chronic & Conservative \\
\hline \multirow[t]{4}{*}{ Kretzler and Richardson (3) } & $1-13$ & Exercise* $^{*}$ & Insertion & Complete & IIID & Acute & Surgery \\
\hline & 14,15 & Exercise* $^{*}$ & Insertion & Complete & IIID & Chronic & Surgery \\
\hline & 16 & Exercise* & Insertion & Partial & II & Acute & Surgery \\
\hline & $17-19$ & Exercise* & Unknown & Unknown & & & To be treated \\
\hline Roi et al (16) & $1-3$ & Bench press & Unknown & Partial & II & & Conservative \\
\hline Liu et al (19) & 1 & Weight lifting & Insertion & Partial & II & Chronic & Surgery \\
\hline \multirow[t]{2}{*}{ Scott et al (21) } & $1-3$ & Other & Unknown & Partial & II & & Consevative \\
\hline & 4 & Other & Insertion & Partial & II & Chronic & Surgery \\
\hline \multirow[t]{4}{*}{ Wolfe et al (5) } & 1 & Sports $^{\dagger}$ & Insertion & Complete & IIID & Acute & Surgery \\
\hline & 2,3 & Sports $^{\dagger}$ & Insertion & Partial & II & & Surgery \\
\hline & $4-7$ & Sports $^{\dagger}$ & MT junction & Partial & II & & Surgery \\
\hline & $8-14$ & Sports $^{\dagger}$ & Unknown & Unknown & & & Conservative \\
\hline Miller et al (6) & 1 & Football & Insertion & Complete & IIID & Acute & Surgery \\
\hline Rijnberg and Van Linge (2) & 1 & Bench press & MT junction & Complete & IIIC & Acute & Surgery \\
\hline Dunkelman et al (1) & 1 & Windsurfing & Insertion & Complete & IIID & Chronic & Surgery \\
\hline Present cases - case 1 & & Bench press & Insertion & Complete & IIID & Chronic & Surgery \\
\hline Present cases - case 2 & & Bench press & Insertion & Partial & II & Chronic & Surgery \\
\hline
\end{tabular}

${ }^{*}$ Nine cases involved bench pressing. ${ }^{\dagger}$ Two of cases \#2 to 7 were chronic; nine cases due to weightlifting, one case due to wrestling, one case due to windsurfing and one case due to rugby. References are numbered by author names as listed at end of paper. MT Musculotendinous 
TABLE 2: Recommended treatment for pectoralis major rupture

\begin{tabular}{lcc}
\hline Extent & Treatment & Result \\
\hline Complete rupture & & \\
Acute & Surgery & Good \\
Chronic (symptomatic) & Surgery & Fair to good \\
Partial rupture & & \\
Acute & Conservative & $\begin{array}{c}\text { Usually good } \\
\text { Chronic (symptomatic) }\end{array}$ \\
\hline
\end{tabular}

described as not returning to "full strength, but did improve significantly," following surgical repair.

The literature supports surgical repair of acute partial ruptures as effective treatment. Four cases of acute partial ruptures were surgically repaired, and were described as successes with criteria such as returning to full function, regaining full range of motion, regaining full strength, and the absence of pain $(3,7,8,10)$. However, seven cases of acute partial ruptures were effectively treated conservatively means $(10,16,21)$. These cases regained full strength, or were able to attain premorbid function if full strength was not attained. Weakness of the pectoralis major may be compensated by other muscles, such as the deltoid or latissimus dorsi. Of the three patients with acute partial ruptures treated conservatively by Roi et al (16), one won a national power lifting championship two years following injury, and one attained a personal best shot-put two years following injury .

The literature supports the surgical repair of chronic partial ruptures that do not respond to conservative management. The five reported cases of chronic partial ruptures accompanied by weakness or deformity indicating the need for surgery $(11,15,19-21)$ had symptoms relieved by surgery. One of these cases also presented with pain (19). Intact tissue in chronic partial ruptures preventing muscle retraction $(19,20)$ enhanced surgical outcome. The three reported cases of injury to the muscle belly also responded well to surgical treatment $(13,18)$.

\section{CONCLUSIONS}

Two cases of chronic rupture are presented. The case of the chronic complete rupture at the humeral insertion was treated by inserting fibrous scar tissue through holes drilled in the humerus, pulling this tissue back on itself, and then interweaving with muscle. The case of the chronic partial rupture at the humeral insertion was unusual in that the central portion of the pectoralis major ruptured rather than the inferior portion. This case was treated by suturing the avulsed portion to the intact sternocostal portion. Both cases experienced good surgical outcomes demonstrated by absence of pain, improving strength, return of full range of motion and correction of deformity.

Review of the literature demonstrated that most injuries occur at the humeral insertion, and most are complete ruptures. The review shows that distinguishing between com- plete and partial injuries is important. Complete ruptures are best treated surgically in the acute situation, and when chronic complete ruptures are present, surgical repair yields good results. Chronic complete ruptures are associated with adhesions, muscle retraction and atrophy. Thus, complete ruptures are more easily repaired in the acute situation than in the chronic. Acute partial ruptures can be effectively managed conservatively or with surgery. The literature does not provide clear direction in their management. Cases of partial ruptures treated conservatively that later present with chronic symptoms can still be managed surgically to good effect.

ACKNOWLEDGEMENT: The authors thank Dr DiPasquale, Warkworth, Ontario, for lending his knowledge of weight lifting injuries.

\section{REFERENCES}

1. Dunkelman NR, Collier F, Rook JL, Nagler W, Brennan MJ. Pectoralis major rupture in windsurfing. Arch Phys Med Rehabil 1994;75:819-21.

2. Rijnberg WJ, Van Linge B. Rupture of the pectoralis major in body-builders. Arch Orthop Trauma Surg 1993;112:104-5.

3. Kretzler HH, Richardson AB. Rupture of the pectoralis major muscle. Am J Sports Med 1989;17:453-8.

4. Jones MW, Matthews JP. Rupture of pectoralis major in weight lifters: a case report and review of the literature. Injury 1988;19:284.

5. Wolfe SW, Wickiewicz TL, Cavanaugh JT. Ruptures of the pectoralis major muscle. An anatomic and clinical analysis. Am J Sports Med 1992;20:587-93.

6. Miller MD, Johnson DL, Fu FH, Thaete FL, Blanc RO. Rupture of the pectoralis major muscle in a collegiate football player. Use of magnetic resonance imaging in early diagnosis. Am J Sports Med 1993;21:175-7.

7. Zeman SC, Rosenfeld RT, Lipscomb PR. Tears of the pectoralis major muscle. Am J Sports Med 1979;7:343-7.

8. Berson BL. Surgical repair of pectoralis major rupture in an athlete. Case report of an unusual injury in a wrestler. Am J Sports Med 1979;7:348-51.

9. Gudmundsson B. A case of ageneisis and a case of rupture of the pectoralis major muscle. Acta Orthop Scand 1973;44:213-8.

10. Marmor L, Bechtol CO, Hall CB. Pectoralis major muscle. Function of sternal portion and mechanism of rupture of normal muscle: Case reports. J Bone Joint Surg [Am] 1961;43A:81-7.

11. Orava S, Sorasto A, Aalto K, Kvist H. Total rupture of pectoralis major muscle in athletes. Int J Sports Med 1994;5:272-4.

12. Delport HP, Piper MS. Pectoralis major rupture in athletes. Arch Orthop Trauma Surg 1982;100:135-7.

13. McEntire JE, Hess WE, Coleman SS. Rupture of the pectoralis major muscle. A report of eleven injuries and review of fifty-six. J Bone Joint Surg [Am] 1972;54A:1040-6.

14. Park JY, Espiniella JL. Rupture of pectoralis major muscle. A case report and review of literature. J Bone Joint Surg [Am] 1970;52A:577-81.

15. Schechter LR, Gristina AG. Surgical repair of rupture of pectoralis major muscle. JAMA 1964;188:1009.

16. Roi GS, Respizzi S, Dworzak F. Partial rupture of the pectoralis major muscle in athletes. Int J Sports Med 1990;11:85-7.

17. Tietjen R. Closed injuries of the pectoralis major muscle. J Trauma 1980;20:262-4

18. Kawashima M, Sato M, Torisu T, Himeno R, Iwabuchi A. Rupture of the pectoralis major. Report of 2 cases. Clin Orthop 1975;109:115-9.

19. Liu J, Wu JJ, Chang CY, Chou YH, Lo WH. Avulsion of the pectoralis major tendon. Am J Sports Med 1992;20:366-8.

20. Lindenbaum BL. Delayed repair of a ruptured pectoralis major muscle. Clin Orthop 1975;109:120-1

21. Scott BW, Wallace WA, Barton MAJ. Diagnosis and assessment of pectoralis major rupture by dynanometry. J Bone Joint Surg $[\mathrm{Br}]$ 1992;74B:111-3. 